\title{
Spatial Structure in Chinese and Japanese Cities: A Comparative Study of the Supergrid and Superblock Structure
}

\author{
Xiao Fei Chen \\ Faculty of Architecture Design and Planning, The University of Sydney, NSW, Australia \\ E-mail: xche3951@Sydney.edu.au
}

\begin{abstract}
Supergrids and Superblocks form an urban structure that extends across large areas of many Chinese and Japanese cities. The grid structures consist of wide roads at a city scale and define Superblocks, each with a network of narrower streets. This paper investigates the form-function interrelationships of these structures from morphological perspectives against a backcloth of theory that stresses an integrated network of streets as the prerequisite for a convenient and synergetic environment, with a specific focus on road/street networks, and mix and distribution of functional activities. Both qualitative and quantitative methods (including space syntax) are used to investigate four Superblocks from two pairs of Chinese and Japanese cities: Xi'an and Kyoto, and Nanjing and Osaka, from three aspects: integration, connection and interaction. The focus of this paper is on the Nanjing-Osaka pair and the findings demonstrate clear but divergent patterns between the two cities, which are indicative of general differences between Chinese and Japanese Superblocks: there are very strong interrelationships between the street network and distribution of activities in the Japanese Superblocks, but these are much less evident in the studied Chinese Superblock and this results largely from the extensive Chinese cultural practice of building walls around compounds. It reveals some structural disadvantages, leading to congestion of traffic and functional activities in some strategic locations in Chinese Superblocks. It also highlights some crucial qualities in the structures of many Japanese Superblocks that can provide inspiration for China's future urban development and possibly for cities in other parts of the world.
\end{abstract}

Keywords: Supergrid and Superblock, Urban Morphology, China and Japan,

\section{Introduction}

Cities present themselves with two important features through their spatial structures: one is generated by the socio-cultural life at local scale displaying differences, while the other is generated by economic life at global scale demonstrating a more generic function ${ }^{1}$ of cities (Hillier 2001, p.10). At the same time, cities are also 'means-ends systems in which the means are physical and the ends are functional': 'physically, (they) are stocks of buildings linked by space and infrastructure', and 'functionally, they support economic, social, cultural and environmental processes' (Hillier 1996, p.149). As a result, cities become 'palimpsests that emerge from multiple layers of creativity, erasure, history, politics, economics and technical invention' (Dovey 2016, p.14).

While socio-cultural influence is an underlying power that configures urban morphology in the past, it is not the fundamental force that supports the operation of a city in the contemporary era. Under the shift of paradigms of what an ideal city should be like, the avenues of thinking about the principles of creating good urban structures also have been changed (Marshall 2009). 

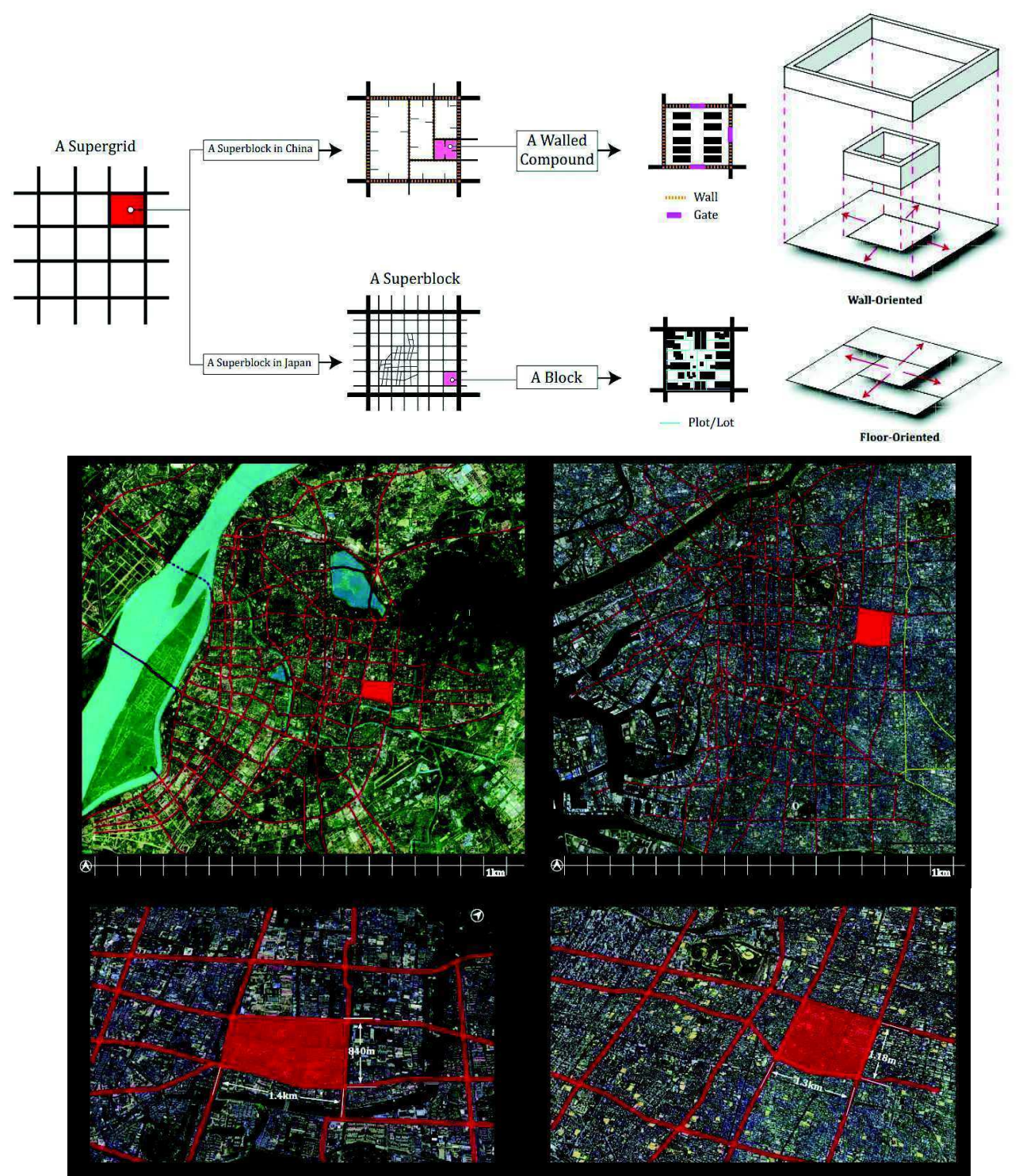

In Nanjing: Daguangli Superblock

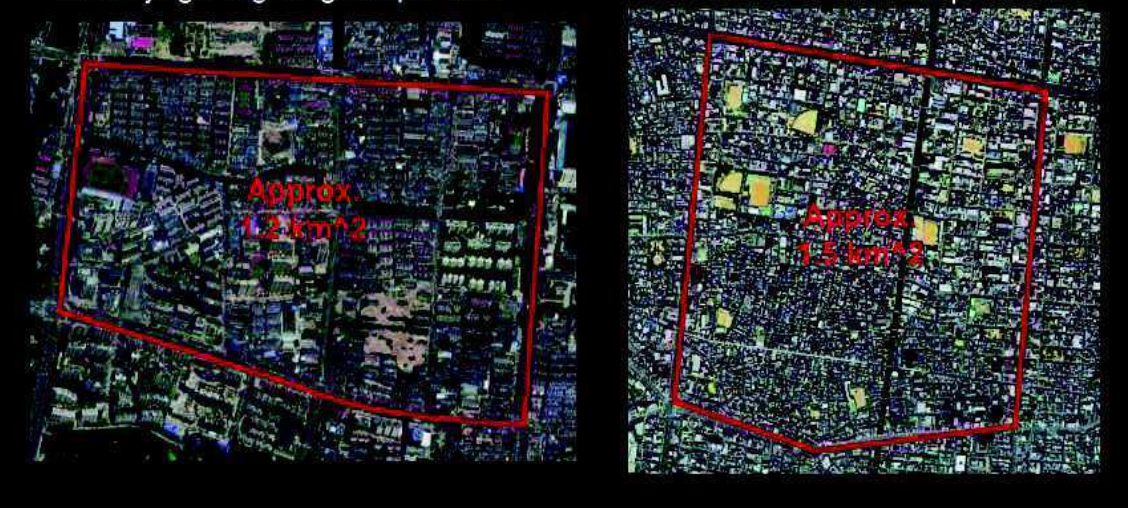

Figure 1.

a. Diagram Illustrating the Supergrid and Superblock structure in China and Japan in relation to the Wall (China) and Floor (Japan) oriented Spatial Conception (Chen 2016).

b. Locations of the Study Sites in the Supergrids on Global/City (b1), Glocal/District (b2), and Local/Superblock (b3) scales respectively. 
Agroup of theorists, including Jacobs (1961), Alexander (1965), Hillier (1984 \& 1996), Bentley et al. (1986), Deleuze and Guattari (1987), Gehl (1987 \& 2010), Arida (2002), Salingaros (2005) and Marshall (2005 \& 2009), are framed collectively by this study as the Interconnection Theory and sets the theoretical and methodological bases for this study. They are concerned with interrelationships between built form (building and space) and function (movement and activity) in cities, and denote that modern cities are supposed to be places where good socio-economic performances, such as trade and exchange, and government services, which are the fundamental functions of a city, take place. They require an effective city form and structure to support them - to assist in the generation and facilitation of socio-economic movements and activities.

Building upon such understanding of cities, this thesis uses those theories to investigate the Supergrid and Superblock structure. This study also argues that it can be considered as an eastern-rooted urban structure that has the power of assisting or deterring different types of functions depending on particular configuration. While both China and Japan share many aspects of culture and have experiences of urban development that are based on the Supergrid and Superblocks as a representation, which is culturally incarnated, codified and utilized in dissimilar ways under a strong Eastern Areal thinking. A multidimensional (Isozaki 1979 \& 2011) and multidirectional (Shelton 2012) spatial conception are nurtured in responsible for the formation of a multi-directional Supergrid as the overarching global network for cities. At the same time, cultural differences between the two countries also result in a more wall-oriented spatial conception in China and a more floororiented conception in Japan (Ashihara 1983 \& 1989, Zhu 2004, Zhu 2010), which further contributes to the different spatial structure of Superblocks in Chinese and Japanese cities respectively (see Figure 1a).

This paper is aimed to discuss the interrelationship between the physical form and social use of space of the Supergrid and Superblock structure through the understanding of the interrelationship between street network and distribution of activities in Chinese cities and Japanese cities. Comparative case study is the major method with a morphological mapping as a tool to convert and organize data into maps. While four Superblocks are selected for research, this paper only focuses on the discussion of the two of them from Nanjing and Osaka as a pair. Figure $1 \mathrm{~b}$ indicates the locations of the two sites in the Supergrid at global/city (b1), glocal/district (b2) and local (b3) scale respectively.

\section{Literatures and Theories}

The central ideas of the Interconnection Theory are threefold: 1) cities are organized and complex systems that are composed of a number of interconnected formal and functional systems through multiple links; 2) The interplay between street structure, movement and activities are the nucleus of the interconnection between form and function; 3) Integration, Connection and Interaction are the three fundamental principles that a well-functioning city structure needs to be able to generate socio-economic synergies as Jacobs' (1961) 'organized complexity'. Without a well-designed physical form that provides connections for movement and facilitates interactions between different parts and across multiple scales in cities, problems will occur: 'extreme compartmentalization and dissociation of internal elements of any organized object will lead to destruction' (Alexander 1965, p.17).

Starting with Jacobs's writing about the complexity and interconnection of cities, Alexander supports her idea by visualizing a semi-lattice organizational structure with the overlapping functions. Both of them prepare the way for other theorists and their studies about the interrelationship between form and function of city structure. On one side, Hillier extends their ideas by introducing the concept of spatial configuration and space syntax as a method of measuring the connection and integration of different parts of a city through its network of spaces (largely streets). This has influenced and complemented by Bentley et al. and Marshall. While Bentley et al. 

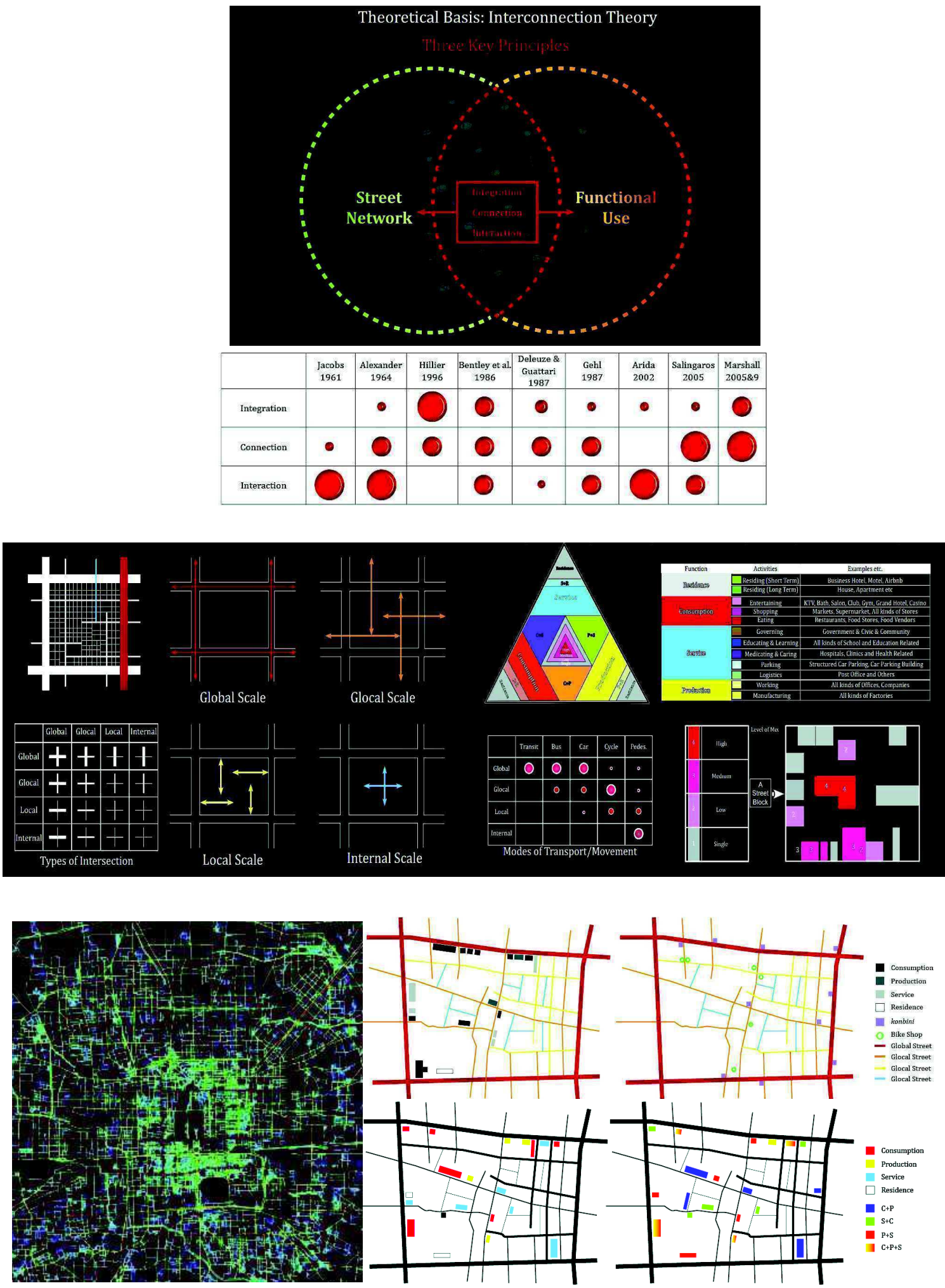

Figure 2.

a. Diagram of Three major principles for creating a good urban structure

b. Diagrams showing the Method for mapping street network and functional activities/uses

c. Example Maps of Integration (left), Connection (top right) and Interaction (bottom right) by using the Proposed Methods. 
simplifies Hillier's method of assessing the permeability of street structure, Marshall develops Hillier's method and creates a route structure to complement the disadvantages of Hillier's method. Delexue and Guattari 1987 on the other hand provides a much more abstract and philosophical understanding of the multiplicities of assemblage and rhizome of cities' complexities, and it echoes Jacobs' complex organism and Marshall's evolving eco-system.

In different ways, Jacobs' and Alexander's ideas were also adapted by Arida and Salingaros. Arida applies the metaphor of quantum physics to complement Alexander's idea by accenting on the importance of interactions and overlapping of different functions, while Salingaros applies the analogy of the human brain to supplement Alexander's idea, emphasizing the importance of multiple-connections between human activities that can sustain self-organization of ordered and complex city networks. The two interpretations of the importance of connection and interaction in cities both echo and clarify what Jacobs had claimed and accentuated in the first place: cities are 'organized complexity' and they are 'replete with unexamined but obviously intricate interconnected and surely understandable, relationships' (Jacobs 1961, p.452).

Not only is there a strong connection between different theorists, each theory from the group has a different emphasis on what kind of principles and built form can contribute more to the stimulation of movement and activity (see Figure 4). While Jacobs emphasizes the short block and a mixed environment, Alexander focuses on a semi-lattice movement structure with overlapped functions; Hillier claims the connection of spatial configuration at multiple scales; Salingaros accents on the multiple links between different nodes; Arida places stress on multiple interactions between elements through a dualistic lens; while Marshall focuses on most desirable types of street pattern. Gehl is different again exploring form and functional integration at a micro scale.

\section{Methodology}

With such theoretical basis as discussed above, this study develops a method to investigate the Supergrid and Superblock structure by using the comparative case study as the major approach. While morphological mapping is the underlying tool that is used to map and analyze the structure and characteristics of the selected sites, it is created by this study based on the Interconnection Theory and on-site field survey. The collected morphological data are converted to maps that can be classified into two sections: 1) Investigation of the street network pattern and the distribution of different types of activities. They are classified and mapped by using the two proposed frameworks as discussed below; 2) Investigation of the Integration, Connection and Interaction of the selected Superblocks. Hillier's Space Syntax is used to measure Integration, while Connection and Interaction are measured by superimposing functional activities maps on top of street network maps to reveal certain interrelationships between the two. This paper only discusses the findings from the Nanjing Osaka pair.

\section{Section One: Mapping the Street Network and Functional Activities}

The Structural Framework for Mapping the Street Network: This Framework is used to map the street network of the selected Superblocks by using the methods from Hillier and Marshall's theories of street connection, and their mapping techniques plus some inspirations from Bentley et al. 1986, Salingaros 2005, Marshall 2005 and Shelton 2012. Different types of connections (roads, streets and gates) are classified into four major categories (see Figure 2b1):

-Global Road: Wide arterial roads that form the Supergrid that are typically more than $25 \mathrm{~m}$ wide

-Glocal Street: Streets that connects neighboring Superblocks by go across Global roads. Global sidewalk streets ${ }^{2}$ are also included as part of the glocal street network.

-Local Street: Usually are streets within a superblock that create direct access to global roads at the edges. Gates that are directly connected to the global roads are included in local street network and are called local gates/ 
a. 3d Model: Daguangli Superblock in Nanjing (left) and Imazato Superblock in Osaka (right)
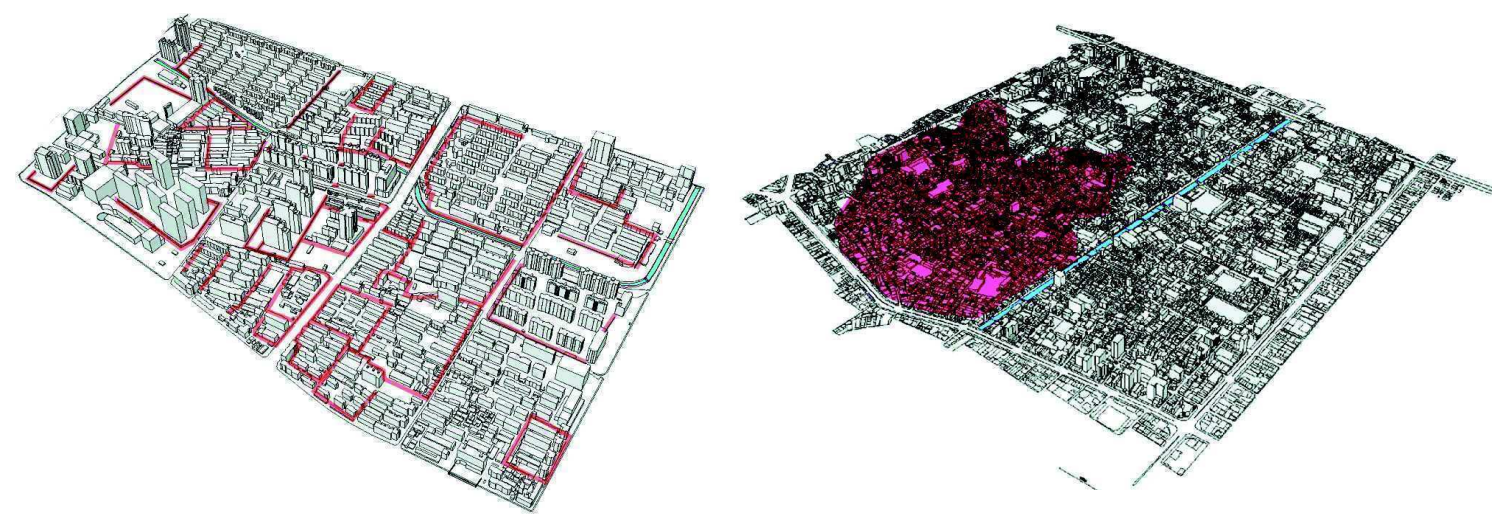

b. Street Network: Daguangli Superblock in Nanjing (left) and Imazato Superblock in Osaka (right)
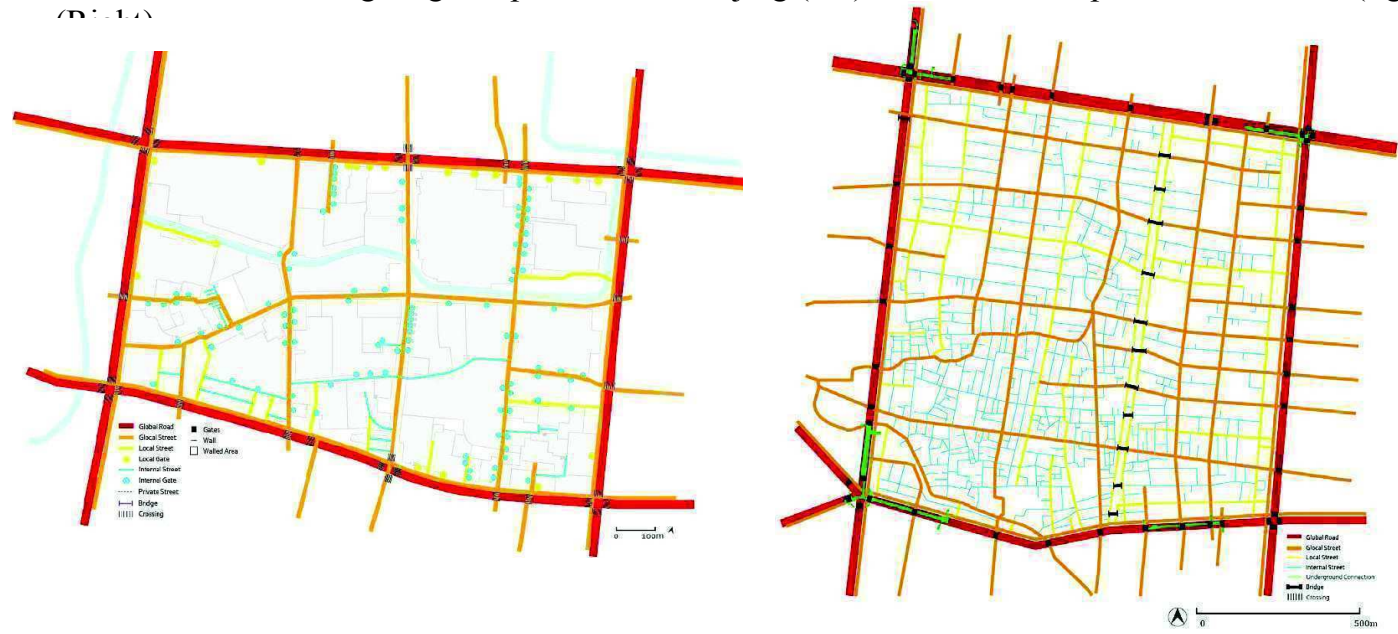

c. Functional Use: Daguangli Superblock in Nanjing (left) and Imazato Superblock in Osaka (right)
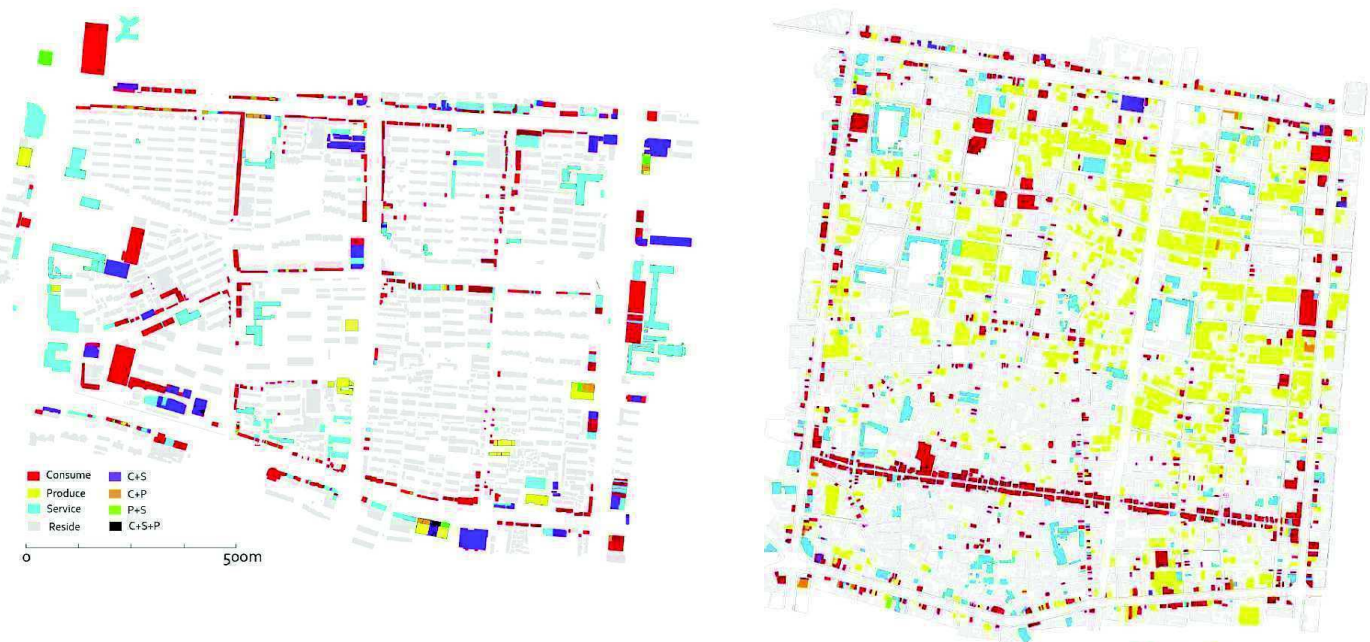

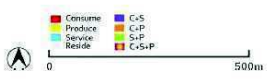

Figure 3 
cul-de-sacs. Streets are indicated as yellow lines while gates are in yellow dots on maps -Internal Street: Local streets that are internal and do not connect directly to the edges of a Superblock. Gates that are not directly connected to the global roads are also part of the internal street network and are called internal gates/cul-de-sacs. Streets are indicated as blue line while gates are in blue dots on maps.

The Functional Framework for Mapping (see Figure $2 \mathrm{~b}$ right): This framework is used to build a functional system to map the different uses of space/types of activities. Inspired by Hoek's (2008), Nes, Pont \& Mashhoodi's (2012) and Dovey's (2014) Triangle models and Jacobs' critics, this research creates a Function Mix Model, which classifies different uses and activities into four major categories. Each category contains a number of uses/ activities, which are color-coded and used to convert data into maps to show the spatial distribution of activities and the mixes of uses within Superblocks. Moreover, these different uses/activities are also further converted into maps with another color-coding system: single (grey), low (pink), medium (dark pink) and high (red), which represent four levels of intensity of the mix of activities on both horizontal and vertical level ${ }^{3}$. This is used to show the distribution of the intensity of functional mix (see Figure 2b2).

-Consumption represents a number of wealthusing activities that is related to the use of any commodity or service in cities, such as all kinds of shops, restaurants, entertainment.

-Production: represents a number of wealthcreating activities that is related to the production of commodity or service in cities, such as offices, factories.

-Service: represents a number of activities that is related to the assistance of consuming, producing or living activities in cities, such as all kinds of schools, hospitals, hotels, banks.

-Residential: represents a number of activities that is related to living and residing.

Section Two: The Interrelationships: Integration, Connection, and Interaction

Integration: Use Space Syntax to measure the level of integration of the street structure of selected Superblock in each city based on street maps (Hillier 1996). UCL Depthmap software is used to run the analysis and generate maps and integration values (see example map in Figure 2c.left).

Connection: Superimpose the Street Network maps with Functional Use maps, which are classified into consumption, production, service and residence (see example map in Figure 2c.top right).

Interaction: Superimpose the Street Network maps on top of the Maps that show the distribution of different intensity of the mix of different type of activities on horizontal and vertical level (see example map in Figure 2c.bottom right).

\section{Measurement and analysis}

The two selected Superblocks are indicated as $3 \mathrm{~d}$ models in Figure 3a, and they clearly indicate two very different morphologies of Daguangli and Imazato Superblock. The model on the left indicates a number of buildings (1164 in total) in large footprints standing in spaces that are grouped collectively by a system of wall and gate structure (the red lines). In comparison, Imazato illustrates a large number of very small buildings (9651 in total) that are tightly built next to each other are stitched by an extensive network of streets and little space in between. The area in red has a finer grain in comparison to the other parts. In general, the models show two morphological representatives: a relatively more bulky built form with coarse grain size in the Chinese Superblock in contrast to a flatter built form with very fine urban grain size in the Japanese Superblock respectively.

The Street Network (see Figure 3b): Such different morphologies can also be understood from the mapping of the street network of the two study sites in Figure $3 \mathrm{~b}$. While the glocal street network has the highest street density and internal streets are counted as having the largest in number, the maps also clearly indicate that the predominant type of connection is the glocal-internal sub-network for movements in both Superblocks. However, the Daguangli Superblock indicates a system 


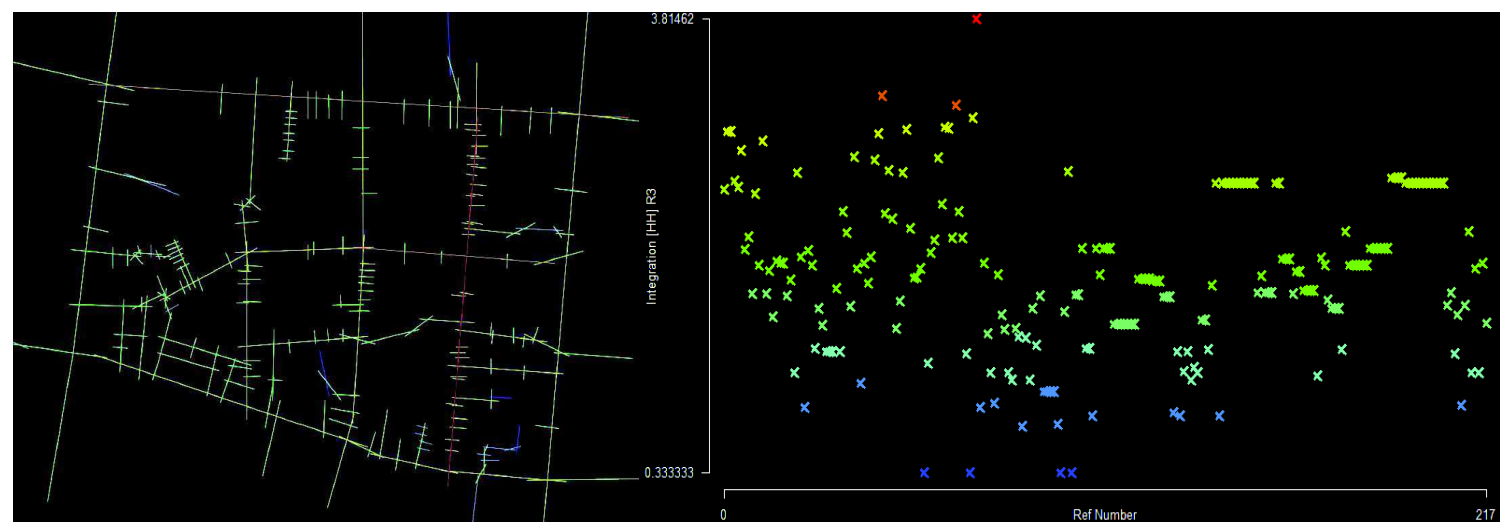

a. Daguangli Superblock in Nanjing and Integration Values in a Scatter Plot

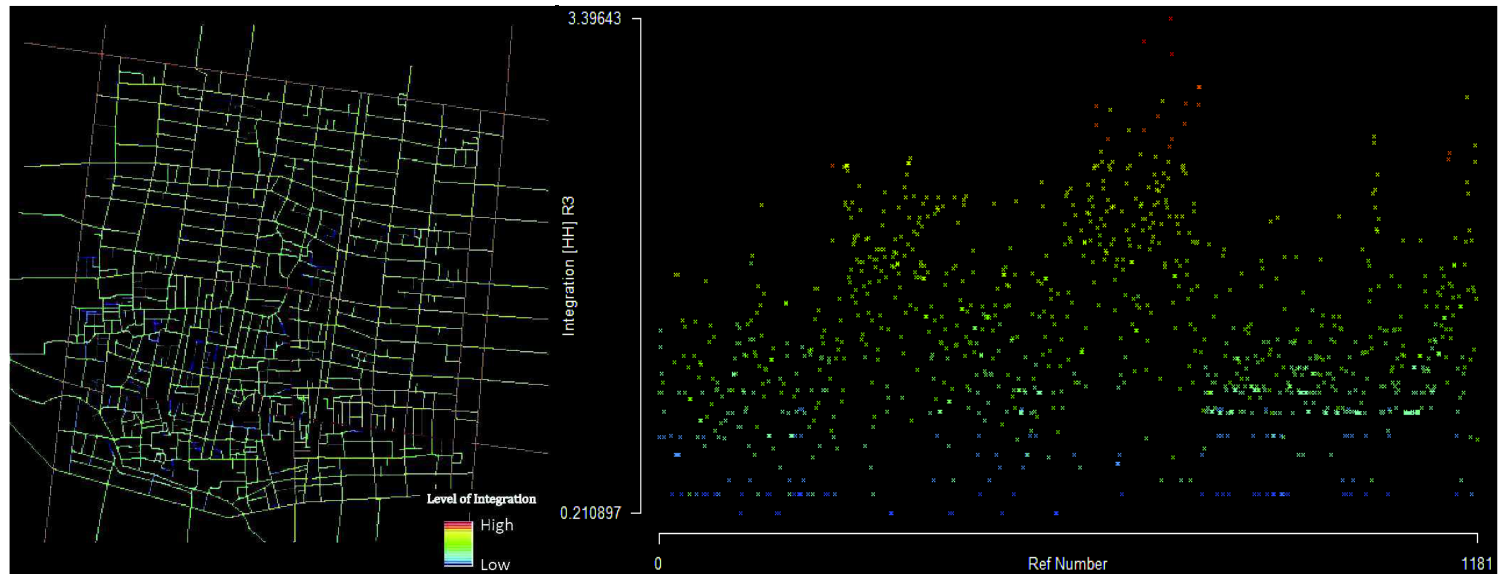

b. Imazato Superblock in Osaka and Integration Values in a Scatter Plot

Figure 4

of wall structure (the grey areas) co-existing with the street network and it forms the 'Global-Local and 'Glocal-internal' as two major sub-networks for movement. Most local (yellow) and internal (blue) streets are actually cul-de-sacs (indicated as dots in maps), which are the gates of many walled compounds. In comparison, the Imazato Superblock illustrates a network of regular and irregular streets that is constructed by the four different types as multidirectional grid. Most internal streets (blue) are concentrated in the south-west quarter of the Superblock, while the other three types are much distributed across the site. According to Marshall's study of street patterns, the former indicates a much-limited connectivity whereas the latter is much better connected. The wall and gate structure in the Chinese Superblocks play the role as part of the street network by controlling and managing the flow of people. In comparison, the wall structure that does not exist in the Japanese Superblock has no effect on the street network, which hence still plays the determinant role in controlling and managing movement and activities.

Functional Use of Buildings (see Figure 3c):

Figure $3 c$ indicates eight types ${ }^{4}$ of functional activities and their distribution in the two study sites. Similarly, different types of activities show a very clear and strong mix in each Superblock on both horizontal and vertical level. Such functional mix resembles the type of environment that Jacobs' 'Greenwich', which can facilitate a number of diverse and active activities to take place and are rehearsed into a street choreography. The maps also illustrate very clear differences. The Superblock in Nanjing shows a clear separation of the residential and non-residential uses, and the concentration of all types of non-residential activities/uses are mostly located on the 
edges and enclosing the residential function into eight segments. In comparison, the functional distribution of Imazato Superblock indicates a much-dispersed distribution, and the concentration of consumption type of activity can be found as a linear shopping street. Another important difference is that the Imazato Superblock has a lot more production type (yellow) of uses and activities, which is very limited in the Daguangli Superblock. Moreover, more mix of different type of activities, especially the mix of consumption and service types, can be found in Daguangli rather than in Imazato Superblock, which is consistent with the flatter built form as found in Imazato.

\section{Integration: Space Syntax and Movement Economy}

Figure 4 indicates the space syntax analysis of the two Superblocks by using the measure of $\mathrm{R}=3$. According to Hillier's theory, the level of integration is in a positive relationship with the magnitude of the intensity of activity and
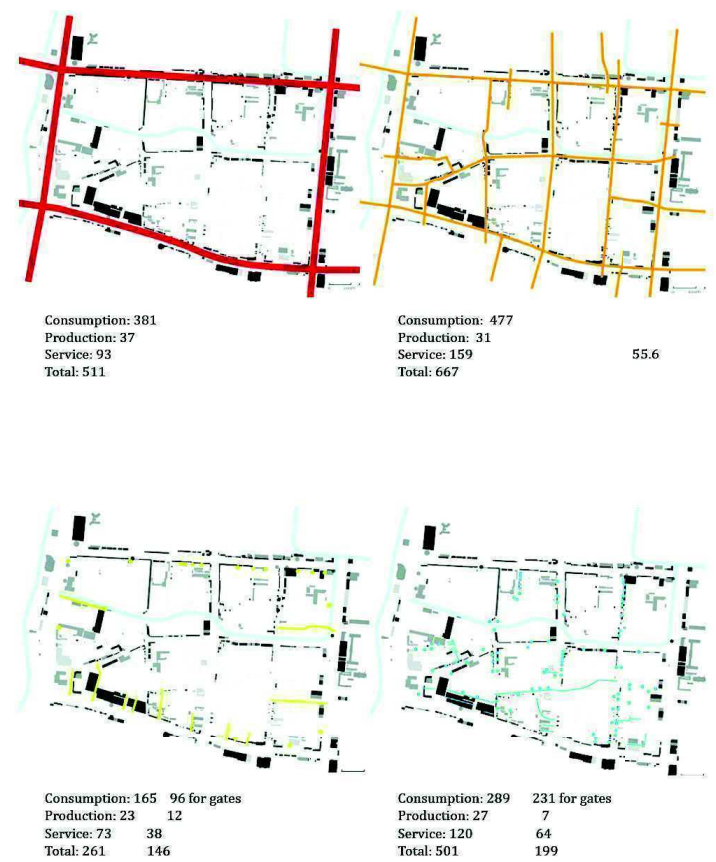

movements. This means that more movement and activities can be found along the streets as indicated in red, orange and yellow than in green and blue.

The results indicate that the two street networks indicate a much higher level of integration in the Imazato than Daguangli Superblock in general. Similarly, the global roads on the four edges are not the most integrated roads in the local network. Both of them have higher concentrations of less integrated streets (mostly internal streets) in their southwest quarters, which also imply less connectivity and fewer movements and activities in the areas.

However, more streets can be found having higher integration value in Imazato than in Daguangli Superblock in general. All global and most of the Glocal and Local streets are measured as more integrated as in red, orange and yellow colors in the former site, whereas those streets are mostly measured as green and blue in the latter site. This also implies that the movement and activities are distributed more evenly across the Imazato than Daguangli Superblock, and this is mostly consistent with
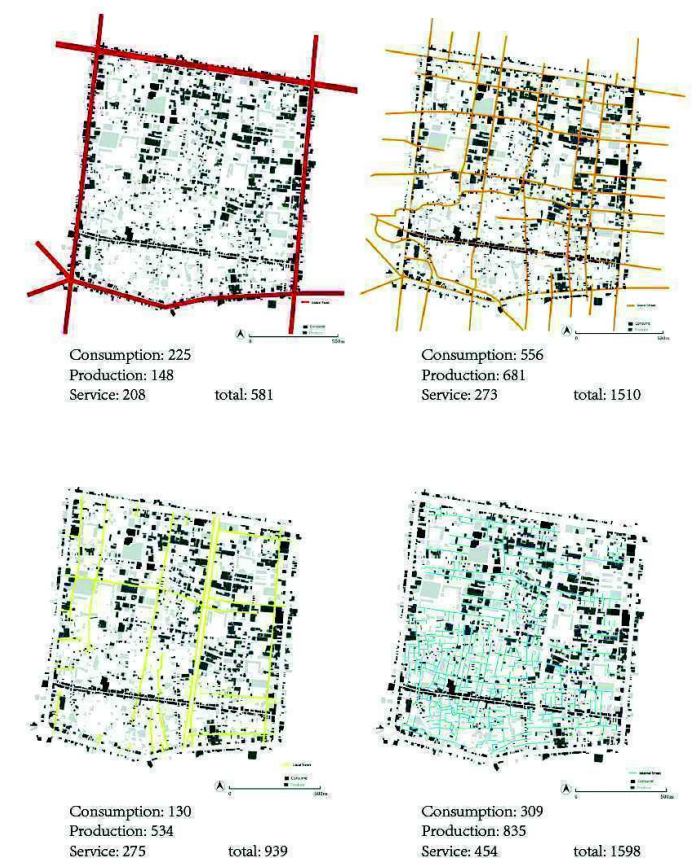

Figure 5

a. Connection between Four types of Streets (Global, Glocal, Local and Internal) and three Major Non-Residential Functional Activities/Uses (Consumption in Black, Production in Grey and Service in Light Grey) in Daguangli (left) and Imazato (right)

b. A Table showing the number of activities along each street type, the number of activities per street density and the density of each street type. 
the distribution of activities as indicated before. More interestingly, the general integration value shows a wider range in the Daguangli (0.33-3.81) than in the Imazato Superblock (0.21-3.39). This again implies a network with more evenly distribution of the connections and activities in the latter than in the former.

\section{Connection: Street Network Pattern and Functional Use of Buildings.}

Figure 5 indicates the relationship between three non-residential type activities (consumption, production and service) and four street types (global, glocal, local and internal). The common distribution pattern of both sites is that various activities more tend to concentrate along the glocal streets, and more activities can be found along glocal and internal streets type of connection in both Superblocks. Moreover, based on the number of activities per street density (No./km/ $/ \mathrm{km} 2)$, the data also shows a stronger relationship to glocal streets. However, it then indicates a strong relation to global roads by excluding the global sidewalk streets, but the difference in numbers between the two types of street is very close. From the maps and data, this indicates very strongly that the glocal street network in both Superblock has a very strong relationship to different types of activities, followed by the global roads. However, the difference between the two Superblocks is that the relationship changes in the Daguangli Superblock, and this is because of the existence of the wall and gate structure. The total number of activities and the number of activities per street density also both indicate a stronger relationship to internal streets by including the internal gates followed by local streets and gates. Because of the absence of such structure in Imazato, there is no change of the relationship.

\begin{tabular}{|l|l|l|l|}
\hline \multicolumn{2}{|c|}{} & Nanjing & Osaka \\
\hline No. of all non-residential activities & Global Roads & 511 & 581 \\
\hline & Glocal Streets & $667(+511)^{5}$ & $1510(+581)$ \\
\hline & Local Streets & $115 / 261$ & 939 \\
\hline & Internal Streets & $199 / 501$ & 1598 \\
\hline No./km/km^2 & Global Roads & 138 & 181.56 \\
\hline & Glocal Streets & $131(235)$ & $146.17(202)$ \\
\hline & Local Streets & $82 / 186$ & 131.3 \\
\hline & Internal Streets & $113 / 286$ & 40.5 \\
\hline Street Density & Global Roads & 3.7 & 3.2 \\
\hline & Glocal Streets & 5.01 & 10.33 \\
\hline & Local Streets & 1.4 & 7.15 \\
\hline & Internal Streets & 1.75 & 39.47 \\
\hline
\end{tabular}

Figure 6 indicates the distribution of the level of intensity of the mix of different functional activities in a $50 \mathrm{mX} 50 \mathrm{~m}$ grid and how it relates to the street network. The two maps on top and bottom illustrate the intensity distribution on horizontal and vertical level respectively. The similar distribution pattern indicates that the higher intensity of the mix on horizontal level is more concentrated along the global roads and glocal streets in both sites, and the intensity of the mix on vertical level is concentrated along the global roads.

However, the Imazato Superblock clearly indicates a much more distributed intensity of the mix of different types of activities on horizontal level. In comparison, Daguangli Superblock has a clear separation between the higher intensity (dark pink and red) and low intensity (grey), the areas with higher intensity tend to enclose the low intensity into about eight areas. On vertical level, the distribution patterns share a similar pattern as 

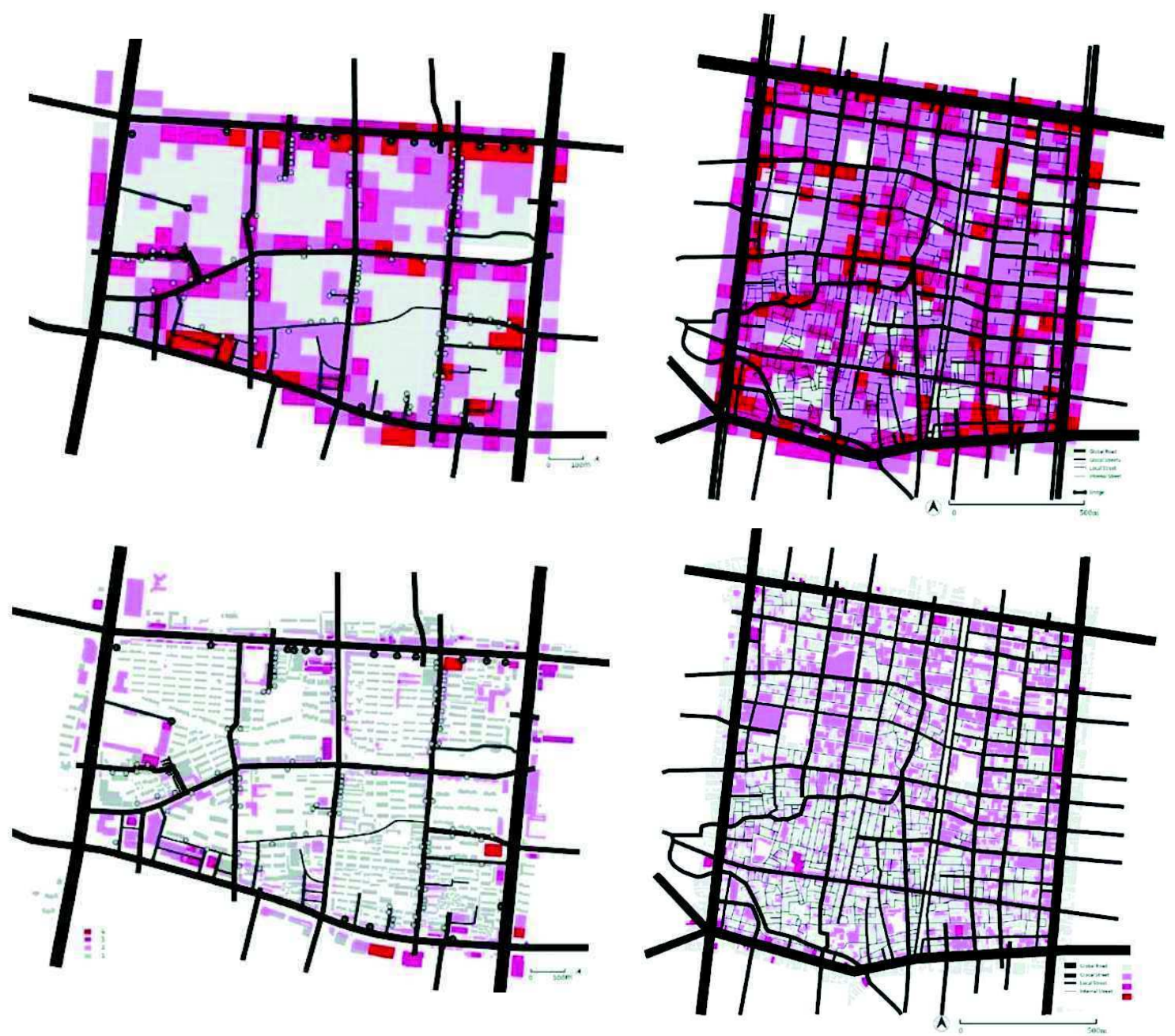

Figure 6

Distribution of the Intensity of the Mix of Functional Activities on Horizontal and Vertical Level in Daguangli (Top) and Imazato (Bottom) Superblock

found in the horizontal level. The intensity of the mix of different types of activities is also very concentrated along the global roads and glocal streets creating eight areas in Daguangli Superblock, whereas the intensity is more dispersed across the whole site with a higher intensity of the mix in general.

\section{Conclusion}

This study demonstrates a comparative investigation of the Supergrid and Superblock structure in China and Japan. This is based on a number of studies since the 1960s that argue that the importance of having an effective urban structure to support and maximize good socioeconomic performances (trade and exchange) and services by generating and facilitating functions like human movement and activities. Based on those theories, this study creates a number of morphological mapping methods to map the street network and functional uses/ activities of two selected Superblocks from the city of Nanjing and Osaka to understand the interrelationships between the form and function of such structure through integration, connection, and interaction.

Among many findings, three major messages can be summarized from the investigation: 1) under the influence of a wall and gate structure, clear but divergent patterns are displayed in the two Superblocks. Strong interrelationships between the street network and distribution of functional use/activities can be found in the Imazato Superblock in Osaka, 
but a stronger relationship between the gates of walled compounds and functional activities is discovered in the Daguangli Superblock in Nanjing. This reveals two very different spatial organization principles, which are influenced by wall and floor oriented spatial conception as argued by this study, and they can represent the characteristics of the form-function relationship in Chinese and Japanese structure; 2) Different structures of connection within studied Superblocks have a deterministic impact on the spatial distribution of human activities and land use. Both Superblocks indicates that Glocal type of street indicates stronger relevance to all non-residential activities, while global road shows a stronger relationship to the consumption type activities in particular. Moreover, the glocal-internal gate type of connection in Daguangli Superblock indicates a stronger concentration of activities around gates, where flows of movements are controlled by those exchange points. In comparison, activities are more evenly distributed along the glocal-internal street type of connection in the Imazato Superblock; 3) While the wall and gate structure in the Chinese case has resulted from a cultural influence, it is also responsible for a less integrated and connected street network within the Superblock with clear concentrations and separations of different uses and activities around the gates, which are located along the global roads and glocal streets. This structural design puts a great pressure on the global roads by creating a lot of congestions created by human movements and activities. In comparison, the Superblock in Japan shows much-distributed activities and uses with a well-connected grid pattern. This indicates a structural advantage of the Superblock structure in the Japanese case that China can learn from to assist the re-design of the Superblock structure and to release the pressure of over-concentration.

\section{Acknowledgement}

All maps and data are collected and created by the author, who is partially funded by the University of Sydney for the on-site fieldwork in the two cities.

\section{Notes}

1 Modern cities present themselves with a common 'generic function', by which Hillier fathoms: 'it is the spatial implications of the most fundamental aspects of human use of space that is the fact of occupation and the fact of movement. At this generic level, function imposes restraints on what is spatially viable, and this is responsible for what all buildings have in common as spatial designs (Hillier 1996 p. 8)'.

2 Global Sidewalk Street is the name of a type of street that is flanked along the global roads. It is mainly used for pedestrian and various activities to take place. This name is adopted from the study of Gokiso Superblock in Nagoya, Japan from Shelton 2012.

3 Horizontal level refers to the functional use of the ground floor of each building on site, whereas vertical level refers to the functional use of buildings on different floors.

4 The eight types include: Consumption, Production, Service and Residence as four primary types. The other four types refer to the mix of consumption and production, consumption and service, production and service and the mix of consumption, production and service. This is indicated in Figure 1.b2.

5 The numbers in orange color indicates the number of activities by including the global sidewalk street as part of the glocal street network. The numbers in green color represents the number of activities by including the activities around local and internal gates.

\section{References}

Alexander, C. (1965). 'A city is not a tree', Architectural Forum 122, 58-62.

Ashihara, Y. (1983). The Aesthetic Townscape, US: Massachusetts Institute Technology Press Halliday Lithograph.

Ashihara, Y. (1989). The Hidden Order, Tokyo through the Twentieth Century, Kodansha International, Tokyo and New York

Arida, A. (2002). Quantum theory, UK: Routledge

Baidu Map, (2015). The city of Xi'an, Retrieved from http://map.baidu.com/. 
Bentley et al., (1985). Responsive Environments: A Manual for Designers, London: Architectural Press.

Deleuze, G., \& Guattari, F. (1980). A Thousand Plateaus, Trans. Brian Massumi. London and New York: Continuum, 2004. Vol. 2 of Capitalism and Schizophrenia, 2 vols. 19721980. Trans. of Mille Plateaux. Paris: Les Editions de Minuit.

Dovey, K. \& Woodcock, I. (eds). (2014). 'Intensifying Melbourne: Transit- Oriented Urban Design for Resilient Urban Futures', Research Report, University of Melbourne, retrieved from https://msd.unimelb.edu. $\mathrm{au} /$ sites/default/files/docs/Intensifying\%20 Melbourne\%202014 180dpi.pdf

Dovey, D. (2016). Urban Design Thinking: A Conceptual Toolkit, Bloomsbury Publishing Gehl, Y. (1987). Life Between Buildings: Using Public Space, Washington, Covelo, London, Island Press

Gehl, Y. (2010), Cities for People, Washington, Covelo, London, Island Press

Google Map 2015, City of Kyoto, Retrieved from http:/www.google.com.au

Hillier, B. (1996) Space is the machine (Cambridge University Press, Cambridge).

Hillier, B. (2001). 'A Theory of the City as Object, how spatial laws mediate the social construction of urban space', presented at: 3rd International Space Syntax Symposium, Atlanta, Georgia, USA. Retrieved from HTTP://DISCOVERY.UCL.AC.UK/1029/

Hoek, Joost. Van Den, 2008, The MXI (Mixed use Index). An instrument for anti-sprawl policy? Proceedings of the 44th ISOCARP congress 2008, Retrieved from http://www. isocarp.org

Isozaki, A. \& Stewar, D. (2011). Japan-ness in Architecture, MIT Press

Jacobs, J. (1961). The death and life of great American cities (New York: Random House).

Nes, Van. Akkelies. Pont, Meta. Berghauser. \& Mashhoodi, Bardia. (2012). 'Combination of Space Syntax with Space matrix and the mixed use index: The Rotterdam South test case', Eighth International Space Syntax Symposium, Retrieved from http://www.sss8.cl/media/upload/paginas/ seccion/8003_1.pdf
Marshall, S. (2005) Streets \& Patterns, Spon Press, Taylor \& Francis Group

Marshall, S. (2009). Cities design and evolution, London; London : Routledge.

Salingaros, N. A. (2005). Principles of urban structure. Techne Press, Amsterdam

Shelton, B. (2012) Learning from the Japanese City: Looking East in Urban Design, Routledge imprint of Taylor \& Francis, London.

Zhu J.F. (2004). Chinese Spatial Strategies Imperial Beijing 1420-1911., Routledge, Curzon

Zhu, W.Y. (2010) Space, Symbol and City: a Theory of Urban Design, China Architecture \& Building Press, Beijing. 